\title{
Changes in serum potassium concentration in asthmatic and normal subjects during exercise
}

\author{
MATTHIAS GUGGER
}

From the Division of Pneumology, Department of Medicine, University of Berne, Inselspital, Berne, Switzerland

\begin{abstract}
Serum potassium concentrations were measured before, during, and after exercise in 32 patients with asthma (12 with exercise induced asthma), and in seven normal subjects. The changes in serum potassium in response to exercise did not differ significantly in the two groups or between those with and without exercise induced asthma. The potassium response to exercise is unlikely to be relevant to the mechanism underlying exercise induced bronchoconstriction.
\end{abstract}

It has been suggested that serum potassium may influence airway smooth muscle responsiveness and may play a part in the pathogenesis of exercise induced asthma. ${ }^{12}$ In normal subjects serum potassium concentrations are known to increase linearly with increasing work intensity. ${ }^{3}$ Recently Haas $e t a l^{2}$ found higher serum potassium concentrations after exercise in asthmatic patients than in normal subjects. As serum potassium is known to be under adrenergic control, ${ }^{4}$ they suggested that these findings were in keeping with an impairment of adrenergic function in asthmatic patients. $^{2}$

The aim of this study was to investigate changes in serum potassium in response to exercise in asthmatic patients with and without exercise induced asthma and in normal subjects.

\section{Patients and methods}

Seven normal non-atopic subjects (six of them men; mean (SEM) age $28(1.7)$ years) and 32 patients (23 of them men; mean age $26(1.4)$ years) with asthmas were studied. Twenty five patients had extrinsic atopic asthma, three extrinsic non-atopic occupational asthma, and three predominantly intrinsic asthma. The normal subjects and 12 of the asthmatic patients were having no medication. Twenty patients were taking inhaled salbutamol, adjusting the dose as required (0-600 $\mu \mathrm{g}$ daily); six used sodium cromoglycate and one oral theophylline occasionally. Drugs were withheld for at least 12 hours before the study. All patients were symptom free and had no evidence of airways obstruction at the beginning of the study. Informed consent was obtained from all subjects and the study was approved by the local ethical committee.

Address for reprint requests: Dr Matthias Gugger, Department of Medicine, University of Berne, Inselspital, CH-3010 Berne, Switzerland.

Accepted 28 February 1989
Physical examination and the chest radiograph showed nothing abnormal. Mean (SEM) values for baseline FEV $_{1} /$ VC (forced expiratory volume/vital capacity) and FEV $1 \%$ predicted) were $80.3(2.2)$ and $101.4(2.7)$ in the normal subjects and $78.4(1.6)$ and $102.5(2.2)$ in the patients. All subjects performed treadmill exercise for six minutes at a slope of $10 \%$, the treadmill speed being adjusted to achieve a heart rate of around 180 beats/min for the last minute. If the FEV 1 fell by more than $10 \%$ at 0,10 , or 20 minutes after exercise the subject was considered to have exercise induced asthma.

Blood was sampled from an indwelling Cournand needle (inserted into a brachial artery before exercise) during the last 30 seconds of exercise and 10 and 20 minutes after exercise, the arterial blood being allowed to flow into the syringe with no tourniquet or suction. Potassium concentrations were determined by flame photometry within one hour of sampling.

Analysis of variance was used for comparisons and a Tukey-HSD post hoc test when appropriate. Values are given as means with standard errors in parentheses.

\section{Results}

Exercise did not result in bronchoconstriction in the normal subjects or in 20 of the asthmatic patients. In the other 12 asthmatic subjects the mean (SEM) percentage falls in FEV 0,10 , and 20 minutes after exercise were 17.5 (3.7), 17.9 (4.5), and $17 \cdot 8(5 \cdot 5)$. The mean maximum percentage fall in $\mathrm{FEV}_{1}$ in the subjects with exercise induced asthma was $24(5 \cdot 3)$, compared with $4.2(0.9)$ in those without exercise induced asthma. The previous treatment for those with exercise induced asthma was similar to that of those without exercise induced asthma ( $5 v 7$ patients having no treatment, $7 v 13$ inhaled salbutamol only, $4 v 2$ inhaled sodium cromoglycate). There was no significant difference between the normal subjects and those with and without exercise induced asthma for treadmill speed $(9.0(0.5), 7 \cdot 8(0.3)$ and $8.3(0.3) \mathrm{km} / \mathrm{h})$, or for maximum heart rate $(187(0.6), 183(3)$, and $186(4)$ beats/ $\mathrm{min})$. The decrease in $\mathrm{pH}$ at peak exercise was significantly greater $(\mathrm{p}<0.05)$ in the normal subjects $(7.17(0.03))$ than in those with $(7.26(0.03))$ or without exercise induced asthma $(7 \cdot 26(0 \cdot 03))$.

There were no significant differences in serum potassium concentration between the three groups at any time (table).

\section{Discussion}

The main finding of this study is that asthmatic subjects had similar increases in arterial serum potassium concentration in 
Mean (SEM) changes in serum potassium concentrations ( $\mathrm{mmol} / \mathrm{l}$ ) before, during, and after exercise in normal subjects and asthmatic patients with and without exercise induced asthma (EIA)

\begin{tabular}{|c|c|c|c|c|}
\hline & \multirow{2}{*}{$\begin{array}{l}\text { Before } \\
\text { exercise }\end{array}$} & \multirow{2}{*}{$\begin{array}{l}\text { Peak } \\
\text { exercise }\end{array}$} & \multicolumn{2}{|c|}{ After exercise } \\
\hline & & & $10 \mathrm{~min}$ & $20 \min$ \\
\hline $\begin{array}{l}\text { Normal } \\
\text { subjects }\end{array}$ & $3.7(0.09)$ & $5 \cdot 6(0 \cdot 18)$ & $3.4(0.08)$ & $3.6(0.08)$ \\
\hline $\begin{array}{l}\text { Patients } \\
\text { with EIA }\end{array}$ & $3.7(0.04)$ & $5 \cdot 3(0 \cdot 14)$ & $3.7(0.07)$ & $3.8(0.06)$ \\
\hline $\begin{array}{l}\text { Patients } \\
\text { without EIA }\end{array}$ & $3.7(0.05)$ & $5 \cdot 3(0 \cdot 14)$ & $3.7(0.05)$ & $3.7(0.05)$ \\
\hline
\end{tabular}

response to exercise whether or not they developed exercise induced asthma. There was no significant difference in serum potassium concentration between those with and without exercise induced asthma at any time. The serum potassium concentration had returned to pre-exercise values in all three groups 20 minutes after exercise, though bronchoconstriction persisted in the patients with exercise induced asthma. These findings suggest that differences in serum potassium are not relevant to the mechanism underlying exercise induced asthma-by potentiating cholinergic activity in the airways, for example.'

There was no significant difference in serum potassium concentrations at peak exercise between the three groups. The work loads between the two asthmatic groups were well matched. As none of the normal subjects or patients took regular exercise the larger fall in arterial $\mathrm{pH}$ at peak exercise is likely to be the result of a slightly heavier work load in the normal subjects. Nevertheless, the potassium response to exercise was of the same order of magnitude in all three groups. This result is contrary to the results of Haas et al, ${ }^{2}$ who found raised venous serum potassium concentration in asthmatic subjects "at peak exercise" and 10 minutes after exercise. In their study, however, the "peak exercise" blood samples were taken during the first minute after exercise, a time at which serum potassium is known to fall rapidly. ${ }^{46}$ Ten minutes after exercise serum potassium concentration was slightly higher in the asthmatic than in the normal subjects in the present study, though the difference was not significant $(\mathrm{p}$ $=0.06$ ). Some of the discrepancies between the two studies might be due to variations in timing of blood samples and $\bar{\partial}$ differences between arterial and venous serum potassium $\frac{C}{\sigma}$ during periods of rapid change. ${ }^{6}$ With arterial blood potas- $\frac{\bar{\sigma}}{\bar{T}}$ sium concentration is independent of the site of puncture and $\vec{\nabla}$ of peripheral influences such as local muscle activity and $\varrho$ haemolysis. Different exercise protocols were applied in the two studies and most patients in the study of Haas et al $^{2}$ had $\vec{\circ}$ some pre-exercise airways obstruction, unlike the patients in our study. The mean maximum post-exercise percentage fall $\vec{\omega}$ in $\mathrm{FEV}_{1}$ was $24 \%$ in the current study compared with $16 \%$ in the study of Haas et al. ${ }^{2}$

In the current study the potassium response to exercise was similar in asthmatic patients with and without exercise $\vec{A}$ induced asthma and is thus not likely to be relevant to the mechanism of exercise induced asthma.

I thank Mr K Kyd for his expert technical assistance and $\mathrm{Mr}$ 음 A Caine for his help with editing.

\section{References}

1 Murlas C, Ehring G, Suszkiw J, Sperelakis N. $\mathrm{K}^{+}$-induced alterations in airway muscle responsiveness to electrical field stimulation. J Appl Physiol 1986;61:61-7.

2 Haas F, Levine N, Axen K, Perelman SI, Pineda H, Haas A. Changes in serum $\mathrm{K}^{+}$in healthy and in asthmatic subjects during exercise. Am Rev Respir Dis 1988;137:833-6.

3 Wilkerson JE, Horvath SM, Gutin B, Molnar S, Diaz FJ. Plasma @ electrolyte content and concentration during treadmill exercise $\overline{\overline{ }}$ in humans. J Appl Physiol 1982;53:1529-39.

4 Williams ME, Gervino EV, Rosa RM, et al. Catecholamine modulation of rapid potassium shifts during exercise. $N$ Engl $J$ Med 1985;312:823-7.

5 American Thoracic Society. Definitions and classification of chronic bronchitis, asthma, and pulmonary emphysema. Am 응 Rev Respir Dis 1962;85:762-8.

$6 \mathrm{Lim}$ M, Wolff CB, Band DM. Propranolol, exercise, and arterial plasma potassium. Lancet 1981;ii:591. 